\title{
Students' and Teachers' Decision-Making Fit Before and After the Transition to Junior High School
}

\author{
Carol Midgley \\ Harriet Feldlaufer \\ The University of Michigan
}

\begin{abstract}
Student and teacher perceptions of actual and preferred student decisionmaking opportunities in mathematics classrooms are assessed before and after the transition to junior high school in a longitudinal sample of 2210 students in 117 pre-transition and 137 post-transition classrooms. The findings include: (a) students and teachers perceive fewer actual student decision-making opportunities after than before the transition; (b) students express a preference for more decision-making opportunities while teachers believe students should have fewer opportunities after than before the transition; and (c) the congruency between students' actual and preferred perceptions declines after the transition while teacher perceptions both before and after the transition are highly congruent. It is suggested that there is a "developmental mismatch" between maturing children and the classroom environments they experience before and after the transition. This mismatch may be related to the negative changes in student beliefs and behaviors that have been observed when students enter junior high school.
\end{abstract}

Recently there has been considerable interest in the effect of the transition from elementary to middle or junior high school on early adolescent development. A

This research was made possible by grants from the National Institute of Mental Health (MH31724 - to Jacquelynne S. Eccles), the National Institute of Child Health and Human Development (HD17296- to Jacquelynne S. Eccles), and the National Science Foundation (BNS-8510504-to Jacquelynne S. Eccles and Allan Wigfield).

We thank the members of the Achievement Research Laboratory at the Institute for Social Research for their helpful comments. 
number of studies have been conducted or are underway investigating the nature of this relationship and the possible mediators between the transition and early adolescents' motives, beliefs, values, and behaviors (Harter, Whitesell, \& Kowalski, 1986; Hawkins \& Berndt, 1985; Nottelmann, 1982; Schulenberg, Asp, \& Petersen, 1984; Power, 1981; Simmons, Blyth, Van Cleave, \& Bush, 1979; Thornburg \& Jones, 1982; Trebilco, Atkinson, \& Atkinson, 1977). Eccles (Parsons), Midgley, and Adler (1984) have hypothesized that changes at the classroom level during the transition to junior high school are causally related to changes in early adolescents' belief systems. They point to two characteristics of the classroom environment that may be especially important: organizational and evaluative practices that focus students on ability selfassessment, and opportunities for student self-management and autonomy.

In the area of student self-management there is limited evidence that after the transition to junior high school early adolescents have fewer choices, participate less in decision-making, and have fewer opportunities to take responsibility than before the transition (Rounds \& Osaki, 1982; Trebilco et al., 1977). It should be pointed out, however, that the Trebilco study followed Australian early adolescents to a technical school and high school and the Rounds and Osaki study, the most comprehensive study to date comparing classroom practices before and after the transition, was limited to one junior high school. We have suggested that a "developmental mismatch" may occur between maturing adolescents, who want more imput into classroom functioning, and the opportunities afforded them in the classroom, and that this mismatch may be related to negative changes in students' belief systems, especially in the academic domain (Eccles et al., 1984; Feldlaufer, Midgley, \& Eccles, 1987).

Studies that have assessed student and teacher perceptions of actual and preferred classroom environments indicate that both students and teachers want students to have more opportunities for self-management than they actually experience in their classrooms (Fisher \& Fraser, 1983; Fraser, 1982; Fraser \& O’Brien, 1985; Lee, 1979; Lee, Statuto, \& Kedar-Voivodas, 1983; Mac Iver, Klingel, \& Reuman, 1986; Moos, 1979; Reuman, Mac Iver, Klingel, Midgley, Feldlaufer, \& Hermalin, 1984). Studies investigating the effect of congruency or discrepancy between students' perceptions of the way their classroom actually is, and the way they would prefer it to be, find congruency to be related to increases in achievement and more positive attitudes toward science (Fraser, 1981; Fraser \& Fisher, 1983), and to a broad range of values, beliefs, and behaviors within the mathematics domain (Mac Iver et al., 1986; Reuman et al., 1984). In the Reuman et al. cross-sectional study in ten junior high school classrooms, congruent students had a higher self-concept of ability in math and were more likely to view math as interesting and useful, and the effort required to do well in math worthwhile, than the discrepant students. Congruent students more often reported interest in school subjects and less often reported social activities at school or mandatory attendance as reasons for coming to school, and were less likely to misbehave at school than discrepant students. In a recent longitudinal follow-up study involving 2239 sixth graders in 117 classrooms, 
student decision-making congruency in mathematics was associated with positive value and affect concerning mathematics as well as high effort and expectancies for success, but was not related in the same way to similar outcomes in social and athletic domains. Congruence was inversely related to student misbehavior at school (Mac Iver et al., 1986).

Taking a developmental approach, Lee and his colleagues (Lee, 1979; Lee et al., 1983) assessed second, fourth, and sixth grade students' and teachers' perceptions of their school experience, including their perceptions of actual and preferred decisionmaking opportunities. In general, there were highly significant grade level differences for students but not for teachers. Students felt significantly less constrained as grade level increased, particularly between the second and fourth grade. Across the three grade levels, teachers' preferences remained constant but students expressed a desire for more prerogatives. Students reported some discrepancy between their ideal and actual decision-making status, asserting that they ought to have more prerogatives than those they perceived available to them. Teachers were much more congruent in their actual and ideal perceptions than students at all three grade levels. There was a grade-related decrease in students' congruence due to a greater increase in students' perceptions of what they should be able to do than of what they actually perceived they could do. Lee suggests that:

Children's escalating assertion of ideal prerogatives with age is probably reflective of their developing sense of autonomy and personal competence, combined with an increasing familiarity with the school environment. The absence of concomitant increments in their actual prerogatives suggests that schools fail to support the child's emerging expression of competence. This pattern of decreasing congruence also suggests the possibility of increasing tension between children and school in the upper elementary grades and might be an early precursor to the well-documented alienation, vandalism, truancy, and violence that emerge in the secondary school (Lee et al., 1983, p. 845).

Our study extends the work of Lee and his colleagues in several important ways. First, this research was conducted with a large representative sample of students and teachers in eleven school districts. Second, this is a longitudinal study of students and the teachers they had for mathematics for sixth and seventh grade. Third, this study looks at perceptions of actual and preferred decision-making opportunities and changes in congruency before and after a major school transition. We hypothesize that:

1. Students and teachers will perceive fewer actual decision-making opportunities after than before the transition to junior high school;

2. Students will express a preference for more decision-making opportunities after than before the transition;

3. Students' actual and preferred perceptions will be less congruent after than before the transition;

4. Teachers' actual and preferred perceptions will be highly congruent both years. 


\section{METHOD}

Sample

The data reported in this paper were collected as part of a two year, four wave longitudinal study (The Transitions at Early Adolescence Project) investigating the impact of changes in classroom and family environments on early adolescents' achievement-related motives, beliefs, values, and behaviors. Analyses reported here include data collected at two waves of the four wave panel study. The data are from the fall of 1983 and 1984.

Twelve school districts located in middle-income communities in southeastern Michigan were recruited for the Transitions project. These communities are within a fifty mile radius of Detroit and many residents work in automobile-related industries. An effort was made to include districts that varied in their ability grouping and evaluation practices. All teachers in those districts who taught fifth or sixth graders scheduled to make the transition to middle/junior high school were recruited for the Transitions project. In this way, teachers and students in 143 pre-transition classrooms were recruited year one. Students were followed year two into 138 posttransition classrooms. All participation was voluntary: Seventy-nine percent (3248/4410) of all students enrolled year one agreed to particpate; ninety-five percent of the teachers in the participating schools agreed to participate. An attrition rate of 11 percent between years one and two was accounted for largely by students who moved out of participating school districts.

\section{Case Selection}

Only a subset of the teacher and student sample from the Transitions project is used in the analyses reported here. The student sample includes 2210 students who completed a questionnaire both before and after the transition from sixth grade in elementary school to seventh grade in junior high school.' The teacher sample includes the teachers those students had for mathematics before and after the transition to junior high school: one hundred two pre-transition and 56 post-transition teachers. In Michigan teachers are eligible to teach seventh grade with either elementary or secondary certification. Among the post-transition teachers, 23 percent have elementary certification only, 59 percent have secondary certification only, and 18 percent have both. A total of 117 pre-transition and 137 post-transition classrooms in eleven school districts are represented. There are fewer teachers than classrooms because, in some cases, a teacher instructs more than one math class. This is true in particular at the junior high school level.

\section{Measures}

Survey questionnaires measuring a large number of constructs were administered by field staff to students in their mathematics classrooms. Teachers filled out

'Most of the students excluded from this study were from two school districts where policy changed during the course of data collection so that some students did not move to a new school. 
a Teacher Classroom Environment Measure (TCEM), including the decision-making fit items, for each math class in the sample they taught. Five pairs of items measuring classroom decision-making in math were adapted from Lee (1979). Although Lee assessed children's perceptions of privacy, territoriality, and decision-making at school, only items in the decision-making domain were pertinent to our hypotheses. These yoked pairs of items ask students and teachers about students' actual and preferred decision-making opportunities concerning where they sit in math class, how much math homework they receive, what math they work on during class, what the rules are in their classroom, and what is done in class after the students finish math work. For example:

(a) For students: Do you help decide what math you work on during class?

Should you have a say about this?

(b) For teachers: Do your students have a say about what math they work on during class time?

Do you think students should have a say in this?

Each item measuring actual decision-making prerogatives was coded 1 for respondents who said they did not have the prerogative and 2 if they said they did have the prerogative. Similarly, responses concerning ideal or preferred decision-making prerogatives were coded 1 if respondents thought they should not have the prerogative and 2 if they thought they should. For each yoked pair of items measuring actual and preferred prerogatives respondents were coded as discrepant 1 or congruent 2 . Respondents were coded as discrepant if they said they did not but should have a decision-making prerogative, or if they said they actually did but should not have the prerogative. Students were coded as congruent if they said they did not and should not have a decision-making prerogative, or if they said they actually did and should have that prerogative.

The internal consistency (Kuder-Richardson-20 estimate) of the student perceptions of the five actual and five ideal prerogatives was determined using a larger sample (see Mac Iver et al., 1986). As expected, the internal consistency is lower on the five actual items (.24) than on the five ideal items (.63). Children who seek more input into classroom decisions in one area express a desire for similar opportunities in other areas. However, teachers who grant one kind of decision-making prerogative will not necessarily grant the other kinds of prerogatives considered here. For teachers we also computed the internal consistency of the five actual and five ideal prerogatives using Kuder-Richardson-20. These estimates are .37 for the actual and .47 for the ideal items. The low internal consistency for the student actual perceptions and the low to moderate internal consistency for both the actual and ideal teacher perceptions indicated to us that for the purposes of this study, separate items could be used in the analysis. Because there is some degree of association among the variables, particularly the items measuring perceptions of the preferred environment, we have adopted a conservative alpha level when reporting effects.

Analysis

In analyses comparing student perceptions before and after the school transition, pairwise $t$-tests were performed to assess changes in mean scores. Because the 
teachers are different at year one and year two, analysis of variance is used to assess differences in mean scores.

\section{RESULTS}

\section{Student versus Teacher Perceptions of Actual Decision-Making}

In order to investigate whether there are significant differences between students' and teachers' perceptions of student decision-making opportunities in the classroom, analysis of variance was used to test for mean differences between students and teachers on the five actual items at each year. Table 1 contains means and standard deviations of actual and preferred decision-making items for year one and year two. Values in this table can be readily interpreted as percentages. Because items are coded $I$ for No and 2 for Yes, a mean of 1.25 indicates that 75 percent of the respondents answered the item No and 25 percent answered the item Yes. Students' scores were aggregated to the classroom level for these analyses, using within-classroom means of student scores. ${ }^{2}$ Students report significantly fewer actual decision-making opportunities than their teachers report both years (see Figure 1). ${ }^{3}$ Compared to their teachers, students report fewer opportunities to decide where they sit, at year one $(F[1,231]=41.57 ; p<.0001 ; \mathrm{ES}=.68)$ and at year two $(F[1,269]=40.62 ; p<.0001 ; \mathrm{ES}=.62)$; fewer opportunities to decide what math they work on in class, at year one $(F[1,229]=21.27 ; p<.0001$; ES $=.42)$ and at year two $(F[1,271]=6.66 ; p=.01 ; \mathrm{ES}=.24)$; fewer opportunities to decide what the rules are in their class, at year one $(F[1,229]=60.86 ; p<.0001 ; \mathrm{ES}=.80)$ and at year two $(F[1,272]=10.83 ; p=.001 ; \mathrm{ES}=.29)$; and fewer opportunities to decide what to do next after finishing their math assignment, at year one $(F[1,232]$ $=215.94 ; p<.0001 ; \mathrm{ES}=3.00)$; and at year two $(F[1,272]=35.20 ; p<.0001 ; \mathrm{ES}$ $=.57$ ). Regarding the item, how much math homework is assigned, year two students report significantly fewer opportunities to make this decision than their teachers report $(F[1,272]=4.74 ; p=.03$; ES $=.19)$. Year one teachers and students do not disagree on this item; they agree that most students do not have a say about the amount of homework that is assigned. Although these differences between students and teachers were not hypothesized, they are not unexpected.

\footnotetext{
${ }^{2}$ Analyses were also performed using students as the unit of analysis. Results are similar to those using students aggregated to the classroom level.

${ }^{3}$ Although the mean differences are highly significant, the samples of classrooms and students are large and so statistical significance is not sufficient for interpreting the magnitude of effects. We also calculate effect size (ES) for each contrast (Glass, McGaw, and Smith, 1981). When students are compared to teachers, the students' mean score is subtracted from the teachers' mean score, and the difference is divided by the standard deviation of the teachers' score; when students' perceptions of actual and ideal prerogatives are compared, the mean ideal score is subtracted from the mean actual score, and this difference is divided by the standard deviation of the students' actual score; when students' year one scores are compared to their year two scores, the year two mean is subtracted from the year one mean, and the difference is divided by the standard deviation of the year one scores.
} 
TABLE 1

Means and Standard Deviations of

Teachers' and Students' Perceptions of

Actual and Preferred Decision-Making Opportunities

\begin{tabular}{lrrrrrrrr}
\hline & \multicolumn{4}{c}{ Teacher } & \multicolumn{2}{c}{ Student } \\
Item & \multicolumn{2}{c}{ Year 1 } & \multicolumn{2}{c}{ Year 2 } & \multicolumn{2}{c}{ Year 1 } & \multicolumn{2}{c}{ Year 2 } \\
& Actual & Prefer & Actual & Prefer & Actual & Prefer & Actual & Prefer \\
\hline Sit & 1.66 & 1.76 & 1.54 & 1.61 & 1.34 & 1.69 & 1.23 & 1.73 \\
& .47 & .43 & .50 & .49 & .25 & .15 & .27 & .15 \\
Homework & 1.11 & 1.15 & 1.16 & 1.20 & 1.12 & 1.46 & 1.09 & 1.52 \\
& .32 & .36 & .37 & .40 & .13 & .16 & .13 & .18 \\
Classwork & 1.32 & 1.36 & 1.17 & 1.17 & 1.12 & 1.40 & 1.08 & 1.41 \\
& .47 & .48 & .38 & .38 & .13 & .15 & .10 & .17 \\
Rules & 1.69 & 1.84 & 1.26 & 1.41 & 1.32 & 1.70 & 1.13 & 1.57 \\
& .46 & .37 & .44 & .49 & .22 & .15 & .13 & .18 \\
Do Next & 1.99 & 1.98 & 1.86 & 1.86 & 1.72 & 1.59 & 1.66 & 1.69 \\
& .09 & .13 & .35 & .35 & .18 & .15 & .20 & .16 \\
\hline
\end{tabular}

Standard deviations are reported in italics below the means.

Year $1 N=117$ Year $2 N=137$

Students' scores have been aggregated at the classroom level (i.e., within-classroom means of students' scores are used in these analyses).

These findings are consistent with other studies that compare students' and teachers' perceptions of the classroom environment.

\section{Student Perceptions of Actual versus Preferred Decision-Making}

In order to test the hypothesis that there is a mismatch between the actual decision-making opportunities students perceive they have and the opportunities they think they should have, pairwise $t$-tests were perfomed to compare means at both year one and year two. Individual students were used as the unit of analysis here. As was hypothesized, at both years students report significantly fewer actual decision-making opportunities than they prefer on four of the five yoked pairs (see Figure 2). Students say they should be able to decide more than they perceive they actually can decide, with respect to where they sit in math class, at year one $(t[2173]$ $=-26.05 ; p<.0001 ; \mathrm{ES}=1.40)$ and at year two $(t[2142]=-38.93 ; p<.0001 ; \mathrm{ES}$ $=1.85)$; how much homework they receive, at year one $(t[2184]=-29.88$; $p<.0001 ; \mathrm{ES}=2.61)$ and at year two $(t[2144]=-38.35 ; p<.0001 ; \mathrm{ES}=3.31)$; what math they work on during class, at year one $(t[2178]=-24.75 ; p<.0001$; ES $=2.15)$ and at year two $(t[2143]=-29.95 ; p<.0001 ; \mathrm{ES}=3.30$; and what rules are in effect, at year one $(t[2182]=-31.84 ; p<.0001 ; \mathrm{ES}=1.73)$, and at year two $(t[2149]=-37.45, p<.0001$; ES $=3.38)$. In contrast to these four areas of decision-making, we observe a different pattern of findings for the items measuring perceptions of actual and preferred decisions about what students work on after they 


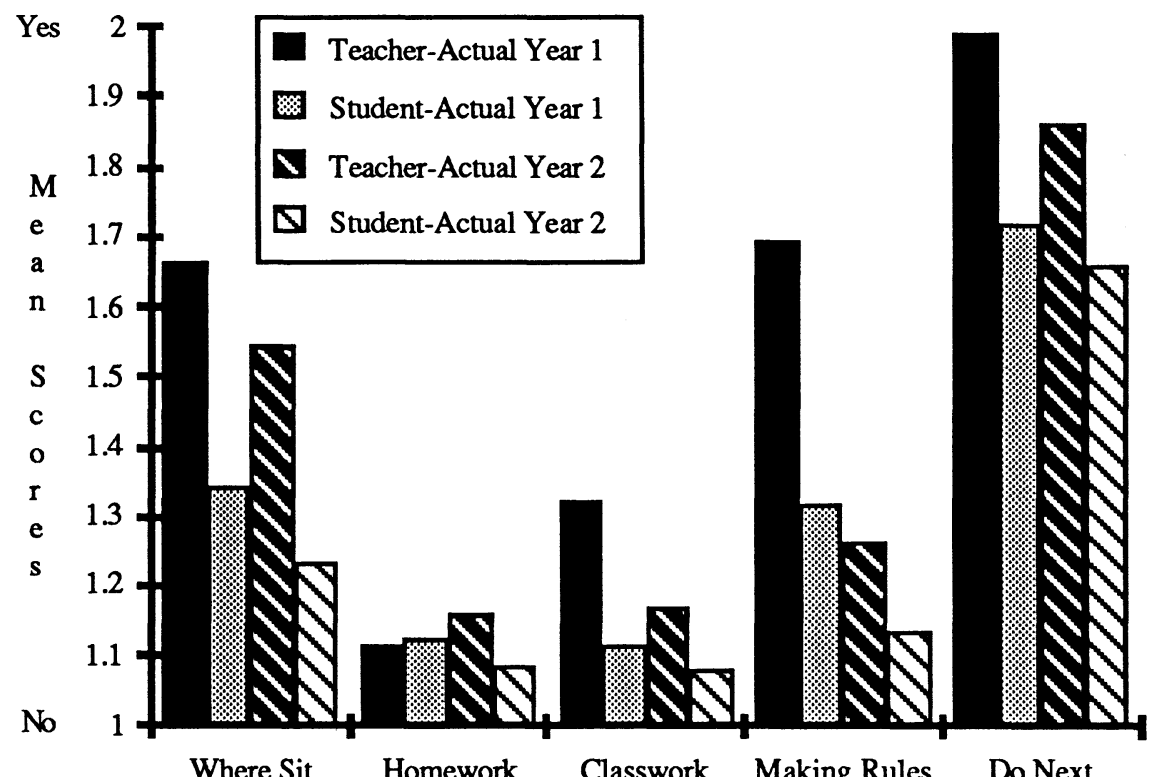

Year 1 Classroom $N=117$; Year 2 Classroom $N=137$; student scores were aggregated at the classroom level using within classroom means.

Figure 1. Teacher versus student actual decision-making.

have finished their math assignments. Pre-transition students would prefer less decision-making power in this area than they perceive they actually have $(t[2176]=$ 9.88; $p<.0001 ; \mathrm{ES}=.72$ ). Post-transition students' reports of actual and preferred opportunities in this decision-making area agree, indicating that their preferences are being met.

Student and Teacher Perceptions of Decision-Making Before and After the Transition.

To assess changes in student perceptions of actual and preferred decision-making opportunities across the school transition, pairwise $t$-tests were performed to compare year one and year two means. Individual students were treated as the unit of analysis here. Analysis of variance was used to assess differences in teachers' means. As we hypothesized, students and teachers report fewer actual decisionmaking opportunities after the transition to junior high school than before (see Figures 3 and 4). After the transition students say they have fewer opportunities to decide where to sit in math class $(t[2130]=8.69 ; p<.0001 ; \mathrm{ES}=.44)$, how much math homework they receive $(t[2133]=6.52 ; p<.0001 ; \mathrm{ES}=.23)$, what math they work on in class $(t[2139]=4.63 ; p<.0001 ; \mathrm{ES}=.31)$, what the rules are in their class $(t[2133]=17.05 ; p<.0001 ; \mathrm{ES}=.86)$, and what they work on in class after finishing their math assignment $(t[2129]=2.11 ; p=.03$; ES $=.33)$. Similarly, post-transition teachers report their students have less say in classroom decisionmaking than pre-transition teachers report with regard to where students sit 


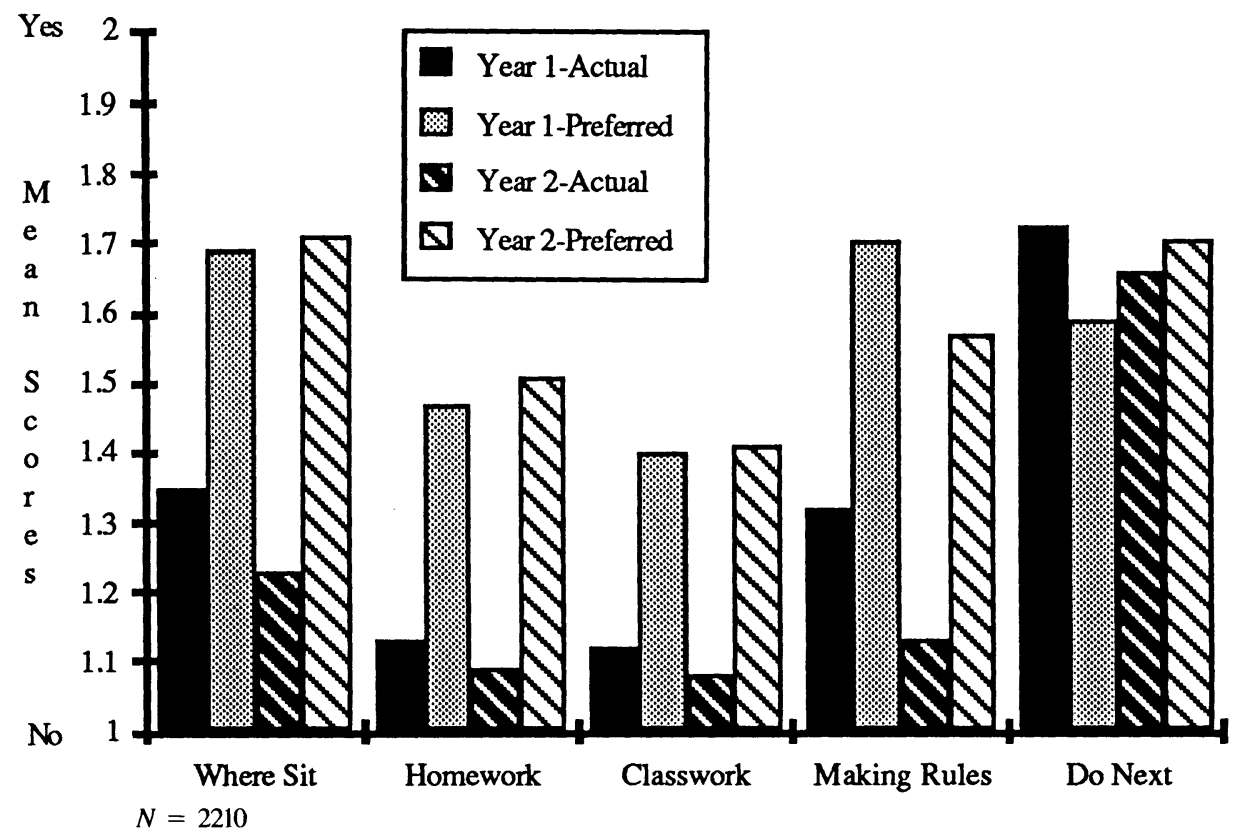

Figure 2. Student actual versus preferred decision-making.

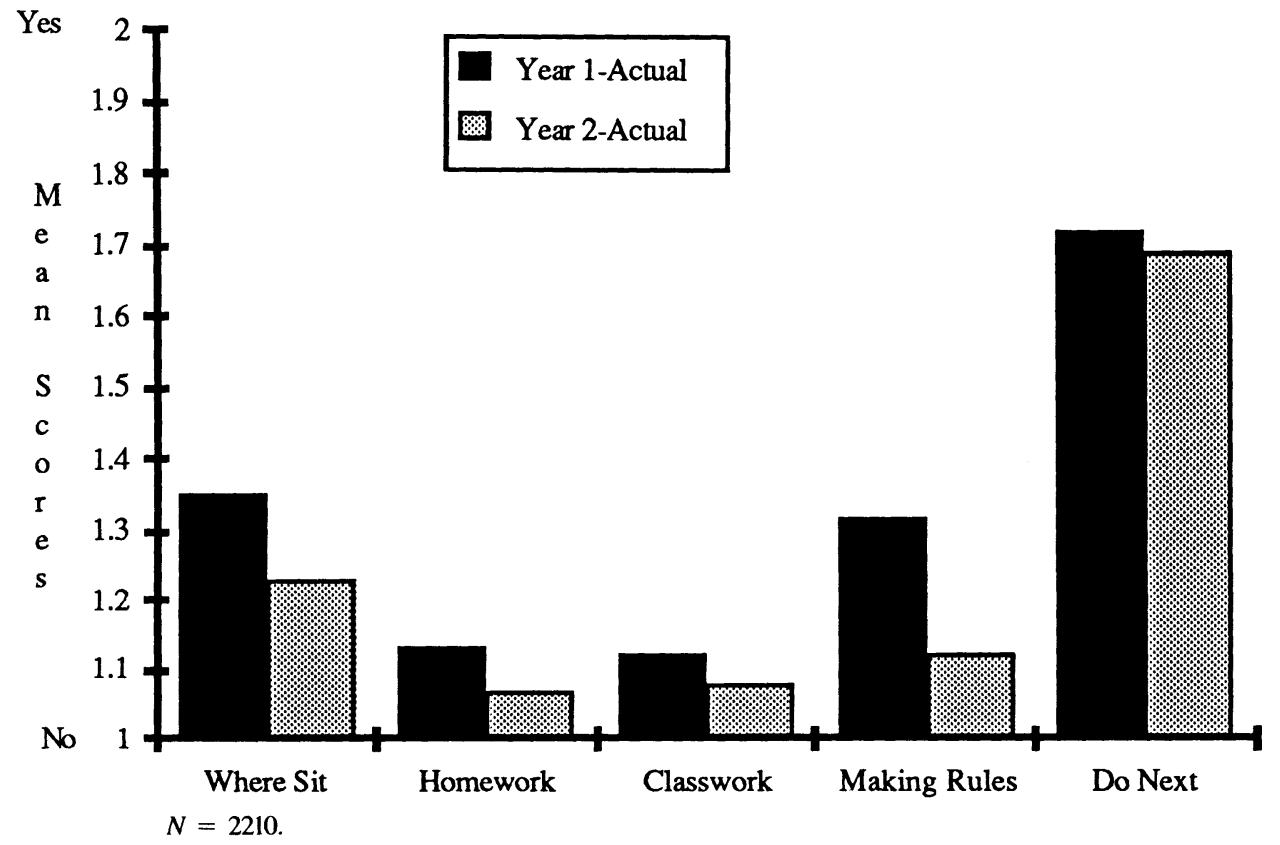

Figure 3. Students-Year 1 versus Year 2 actual decision-making. 


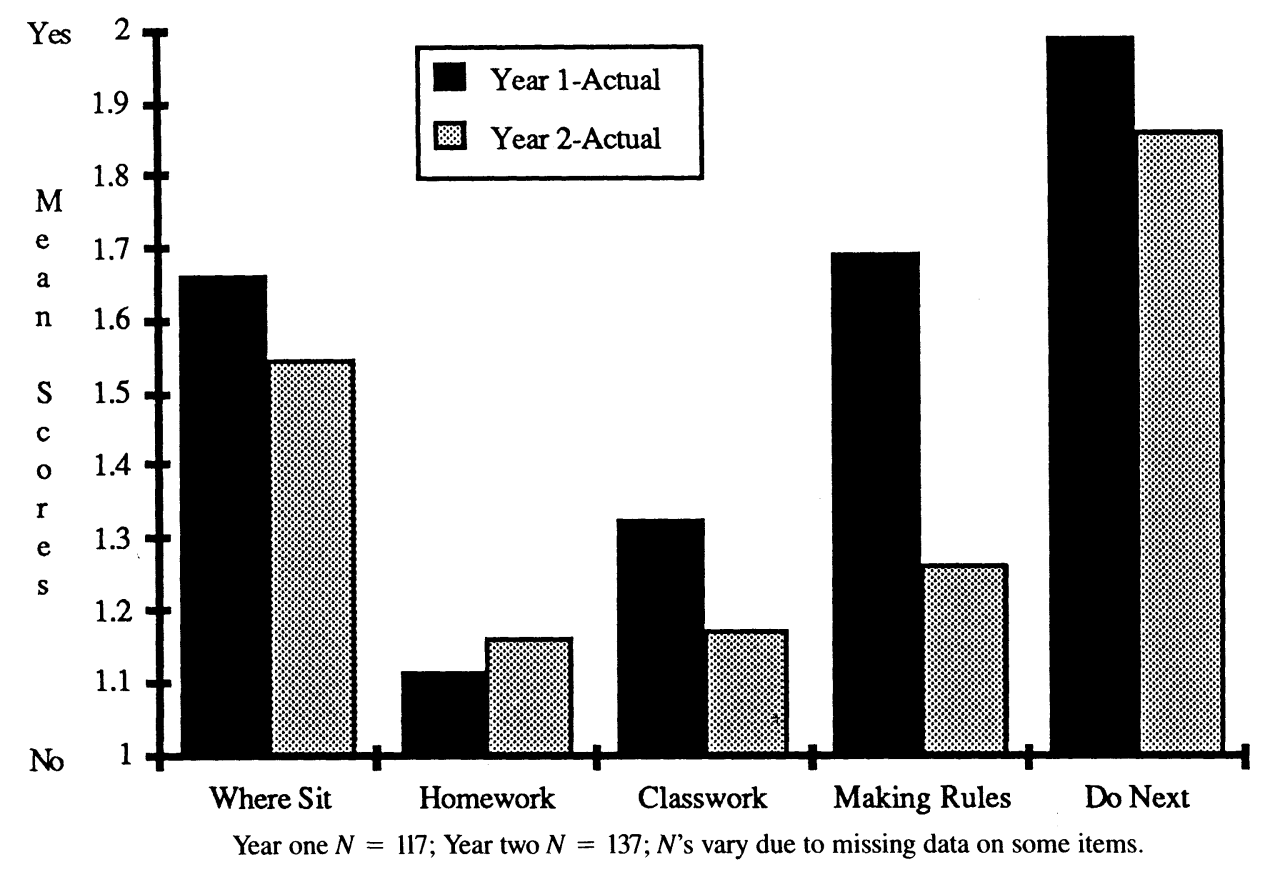

Figure 4. Teachers-Year 1 versus Year 2 actual decision-making.

$(F[1,248]=3.69 ; p=.05 ; \mathrm{ES}=.25)$, what math classwork they do $(F[1,248]=$ $8.43 ; p=.004 ; \mathrm{ES}=.32)$, what the rules are $(F[1,249]=56.45 ; p<.0001 ; \mathrm{ES}=$ $.93)$, and what work students do after they finish their math assignment $(F[1,252]=$ $15.52 ; p=.0001 ; \mathrm{ES}=.37$ ). Futhermore, post-transition teachers think their students should have fewer decision-making opportunities than pre-transition teachers think their students should have (see Figure 5) with respect to seating $(F[1,245]$ $=6.47 ; p=.01 ; \mathrm{ES}=.35)$, classwork $(F[1,244]=11.44 ; p=.0008 ; \mathrm{ES}=.40)$, rules $(F[1,247]=58.51 ; p<.0001 ; \mathrm{ES}=1.16)$, and what to do next $(F[1,252]=$ $12.83 ; p=.0004 ; \mathrm{ES}=.34)$. Both years most teachers agree that students should not have input as to how much homework the students receive. In contrast to their teachers, students think they should have more input into decision-making after the transition than before (see Figure 6) when it comes to deciding how much homework they receive $(t[2129]=-3.37 ; p=.0008 ; \mathrm{ES}=.37)$ and what work to do after finishing their assignment $(t[2120]=-9.24 ; p<.0001 ; \mathrm{ES}=.66)$. The pattern is reversed when it comes to deciding what the rules should be. In this area students think they should have more input before than after they move into junior high school $(t[2132]=10.03 ; p<.0001$; ES $=.86)$. There were not significant differences before and after the transition in students' desires for input into where they sit or what work they do during math class. Both years most students think they should be able to decide where to sit. 


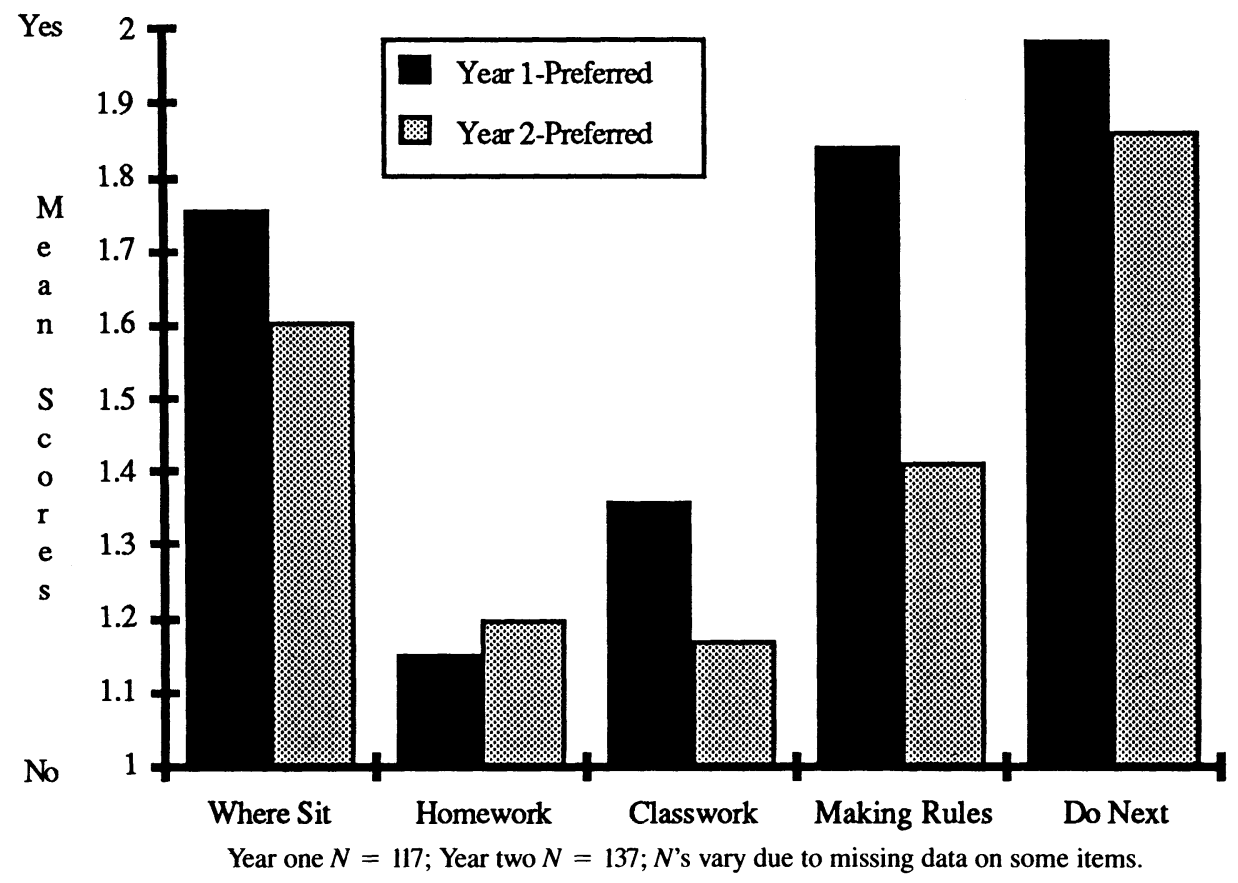

Figure 5. Teachers-Year 1 versus Year 2 preferred decision-making.

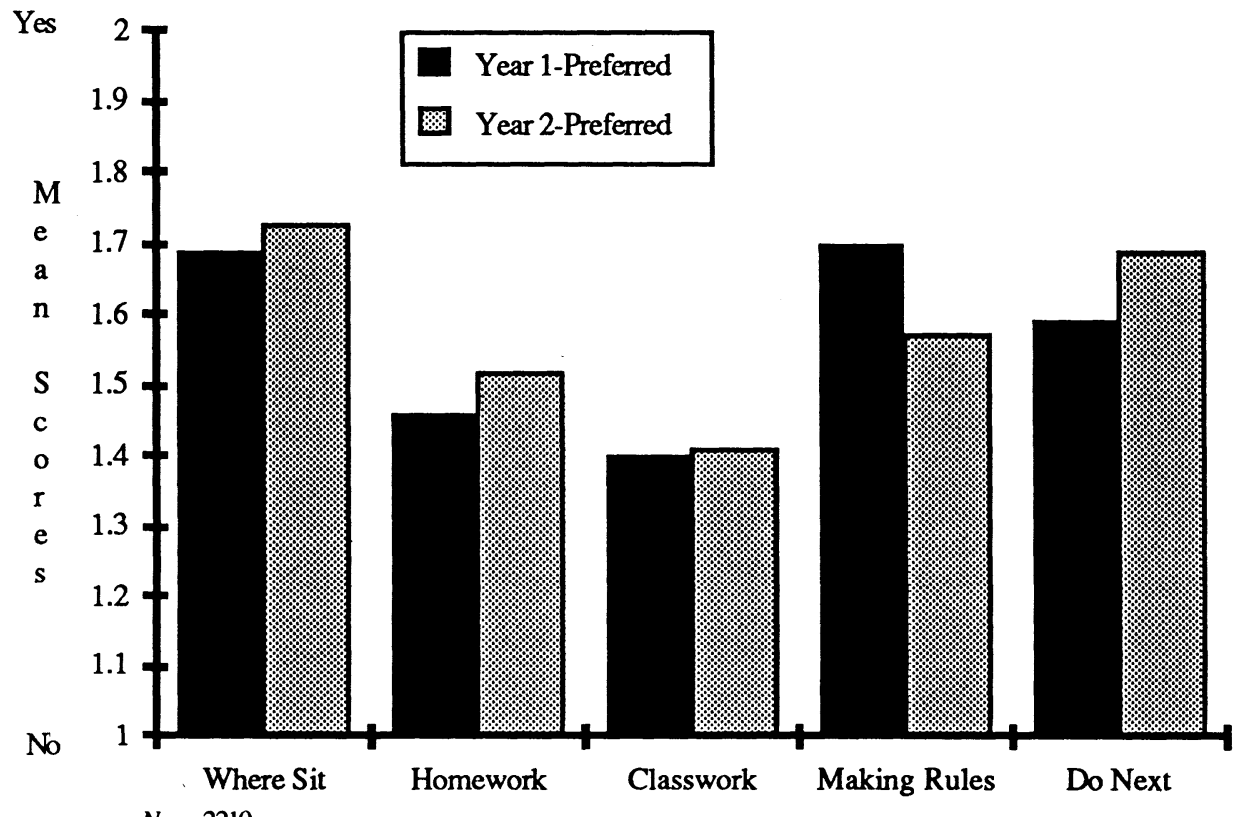
$N=2210$.

Figure 6. Students-Year 1 versus Year 2 preferred decision-making. 
Decision-making Congruency Before and After the Transition

To test for differences between students' decision-making congruency before and after the transition to junior high school, pairwise $t$-tests were performed using congruency scores derived from the five yoked pairs of items. Students were treated as the unit of analysis in these comparisons. Table 2 contains means and standard deviations of teachers' and students' congruency between actual and preferred decision-making opportunities. In three of the five decision-making areas students were significantly less congruent after the transition to junior high school than before, as hypothesized. With respect to deciding where they sit $(t[2108]=4.24 ; p<.0001$; ES $=.41)$, how much homework is assigned $(t[2119]=5.67 ; p<.0001 ; \mathrm{ES}=.53)$ and what the rules are $(t[2122]=2.50 ; p=.01$; ES $=.22)$, the mismatch between students' actual and preferred prerogatives increases after students enter junior high school. This discrepancy is largely accounted for by students reporting they can't but should have these decision-making opportunities. Significant differences in student congruency scores before and after the transition are also found concerning decisions about what work to do after finishing math assignments, however, the findings are in the opposite direction; students are significantly more congruent after than before the transition $(t[2109]=-2.75 ; p=.005 ; \mathrm{ES}=.15)$. This is not surprising in light of the findings reported earlier that before moving to junior high school students think they should have less opportunity than they report they actually have in this area, and after the transition students' perceptions of actual and preferred opportunities are similar.

Finally, our hypothesis that there would not be significant differences between pre- and post-transition teachers' mean congruency was confirmed. Teachers were found to be highly congruent both years on all five yoked pairs. Teachers' mean congruency ranged from 1.87 to 1.99 year one, and 1.85 to 1.96 year two.

In summary, all of our hypotheses received support. Both students and teachers report fewer actual decision-making opportunities after the transition to junior high school than before. In most cases students express a preference for more decisionmaking opportunities after the transition than before; in contrast, post-transition teachers believe students should have fewer decision-making opportunities than do pre-transition teachers. Finally, students become less congruent after they move to the junior high school, while both pre- and post-transition teachers are highly congruent.

\section{DISCUSSION}

There is a striking difference between students' and teachers' reports of actual decision-making opportunities in the classroom both before and after the transition to junior high school. This is consistent with a number of studies conducted at both the elementary and secondary level that have found that teachers perceive their classrooms more positively than their students with respect to involvement and participation (Fisher \& Fraser, 1983; Fraser, 1982; Fraser \& O’Brien, 1985; Moos, 
TABLE 2

Means and Standard Deviations of

Teachers' and Students' Congruency between

Actual and Preferred Decision-Making Opportunities

\begin{tabular}{|c|c|c|c|c|}
\hline \multirow{2}{*}{ Item } & \multicolumn{2}{|c|}{ Teacher } & \multicolumn{2}{|c|}{ Student } \\
\hline & Year 1 & Year 2 & Year 1 & Year 2 \\
\hline Sit & $\begin{array}{r}1.90 \\
.31\end{array}$ & $\begin{array}{r}1.94 \\
.24\end{array}$ & $\begin{array}{r}1.50 \\
.17\end{array}$ & $\begin{array}{r}1.43 \\
.22\end{array}$ \\
\hline Homework & $\begin{array}{r}1.97 \\
.16\end{array}$ & $\begin{array}{r}1.95 \\
.22\end{array}$ & $\begin{array}{r}1.59 \\
.15\end{array}$ & $\begin{array}{r}1.51 \\
.20\end{array}$ \\
\hline Classwork & $\begin{array}{r}1.94 \\
.24\end{array}$ & $\begin{array}{r}1.96 \\
.19\end{array}$ & $\begin{array}{r}1.64 \\
.14\end{array}$ & $\begin{array}{r}1.61 \\
.18\end{array}$ \\
\hline Rules & $\begin{array}{r}1.87 \\
.34\end{array}$ & $\begin{array}{r}1.85 \\
.35\end{array}$ & $\begin{array}{r}1.54 \\
.18\end{array}$ & $\begin{array}{r}1.50 \\
.17\end{array}$ \\
\hline Do Next & $\begin{array}{r}1.99 \\
.09\end{array}$ & $\begin{array}{r}1.96 \\
.20\end{array}$ & $\begin{array}{r}1.63 \\
.13\end{array}$ & $\begin{array}{r}1.65 \\
.17\end{array}$ \\
\hline
\end{tabular}

Standard deviations are reported in italics below the means.

Year $1 N=117 \quad$ Year $2 N=137$

Students' scores have been aggregated at the classroom level (i.e., within-classroom means of students' scores are used in these analyses).

$1=$ Discrepant $2=$ Congruent

1979). In studies that have focused specifically on student opportunities for decisionmaking in the classroom, research shows that teachers believe students can make many more decisions than the students themselves perceive being able to make (Cussen, 1977; Lee et al., 1983; Wolfson \& Nash, 1965, 1968). Is there a lack of communication between teachers and their students, so that students fail to realize that more options are open to them? Social theories of institutional life suggest that teachers, because they are the most powerful people in the classroom, tend to see the setting more positively than those with less power, their students (Cussen, 1977; Moos, 1979; Wolfson \& Nash, 1965, 1968).

At both the pre- and post-transition level students' preferences are out-of-synch with their environment; they would like considerably more decision-making power than they perceive is available to them. Person-environment fit theory states that an individual's behavior is jointly determined by characteristics of the person and properties of the immediate environment. When the needs or goals of the individual are congruent with opportunities afforded by the environment, favorable affective, cognitive, and behavioral outcomes should result for that individual; conversely, when a discrepancy exists between the needs of the individual and opportunities available in that individual's environment, unfavorable outcomes should result (Hunt, 1975; Lewin, 1935; Murray, 1938). In line with this theory, the "lack of fit" 
between students' preferences and the opportunities for decision-making in the classroom environment should predict unfortunate consequences for those students whose needs are not being met. In fact, Mac Iver et al. (1986) confirm this prediction. Students whose desire for decision-making in mathematics was discrepant with the opportunities available in the classroom were less positive about mathematics and about their potential in mathematics than students whose desires and opportunities were congruent. Fraser (1982) suggests that teachers use assessments of student perceptions of actual and preferred classroom environments "as a practical basis for planning environmental changes that will align the actual environment with students' or teachers' preferred environment" (p. 518).

A different pattern of findings was observed for items measuring decisionmaking opportunities and preferences regarding what to work on after math work has been completed. Pre-transition students would prefer less decision-making power in this area; post-transition students' needs are being met. Both years teachers are giving students more opportunities to make decisions in this area than in any other area. Teachers may be more willing to allow students to make decisions for themselves when the required work has been completed.

We believe it is remarkable that both students and teachers say that students receive fewer opportunities for decision-making after than before the transition to junior high school. Even though there is evidence in the literature, cited earlier, supporting this finding, it is commonly believed that as students proceed through the grades they become more capable of making decisions for themselves and that it is the role of the teacher to provide an environment that encourages them toward autonomy. Hunt (1975) stresses the importance of a developmental perspective on person-environment interaction. He believes that "a teacher should not only take account of a student's contemporaneous needs by providing whatever structure he presently requires, but also view his present need for structure on a developmental continuum along which growth toward independence and less need for structure is the long term objective" (p. 221).

Post-transition teachers actually believe students should make fewer decisions than elementary school teachers believe they should make. These differences may be related to organizational features of the junior high school, such as departmentalization, that make it difficult for teachers to adapt to the needs of many different classrooms, or indicate that the junior high school as an institution promotes a negative view of early adolescence so that teachers are socialized to believe that students must be controlled in order to be taught. This finding is consistent with other evidence from The Transitions at Early Adolescence Project. Comparing the beliefs of pre- and post-transition teachers, post-transition teachers were found to trust students less and to be more oriented toward control and discipline than pretransition teachers (Midgley, Feldlaufer, \& Eccles, 1987).

The fact that the discrepancy between students' perceptions of actual and preferred decision-making opportunities increases after the transition lends support to the idea of a developmental mismatch. As these children move through elementary school and into junior high school, they are becoming more knowledgeable, skillful, 
and competent; they are developing cognitively. They express a desire for more control over their lives; they want to have more choices, to make more decisions, to be more influential. These children move into a classroom environment in which they have fewer decision-making opportunities, with a teacher who believes they should have fewer opportunities than did their teacher the previous year. Are we providing classroom environments for early adolescents that are particularly debilitating for that age group? Do we have a developmental mismatch between maturing children and the classroom environments we provide?

These findings point to the importance of including classroom level variables in studies examining the relation between the transition to junior high school and changes in early adolescent beliefs and behaviors, particularly in the academic domain. Insofar as a discrepancy between students' preferences and opportunities in the decision-making area is associated with less positive attitudes toward mathematics and one's potential in mathematics (Mac Iver et al., 1986), and insofar as this study shows that this discrepancy increases after the transition to junior high school, then negative changes in students' motives, beliefs, and values in mathematics after the transition are predictable.

This study was conducted in mathematics classrooms and focuses on only one classroom practice, decision-making, and on only a small subset of decisions that are made in classrooms. The fact that the yoked pair of items assessing perceptions of decision-making about what to do next exhibits a somewhat different pattern than the other decision-making questions leads one to think that various kinds of decision-making opportunities may function differently. This study is also limited because data from teachers were collected at only two time points.

Overall, our findings are quite consistent with previous research that has looked at student versus teacher perceptions, and actual versus preferred decision-making. The Transitions at Early Adolescence Project will be able, in the future, to compare student perceptions of actual and preferred decision-making twice before and twice after the transition, adding to the interpretability of the results. Other studies should expand the scope of decision-making questions and gather students' and teachers' perceptions of actual and preferred practices across a wide range of classroom instructional, organizational, and climate features.

Early adolescence is a critical time for the development and consolidation of attitudes toward the self, values, and aspirations that impact on choices and functioning throughout the life span. With the current upsurge in interest in this stage of life, it is important to consider systematically a broad range of influences on development and to determine what steps we as a society can take to make this a more positive and productive life stage.

\section{REFERENCES}

Cussen, M. P. (1977, April). A comparative study of student and teacher perceptions regarding decision-making in selected open and traditional classrooms. Paper presented at the annual meeting of the American Educational Research Association, New'York. 
Eccles (Parsons), J., Midgley, C., \& Adler, T. (1984). Grade-related changes in the school environment: Effects on achievement motivation. In J. G. Nicholls (Ed.), The development of achievement motivation (pp. 238-331). Greenwich, CT.: JAI Press.

Feldlaufer, H., Midgley, C., \& Eccles, J. S. (1987). Student, teacher, and observer perceptions of the classroom environment before and after the transition to junior high school. Manuscript submitted for publication.

Fisher, D. L., \& Fraser, B. J. (1983). A comparison of actual and preferred classroom environments as perceived by science teachers and students. Journal of Research in Science Teaching, 20, 55-61.

Fraser, B. (1981, April). Validity and use of Individualized Classroom Environment Questionnaire. Paper presented at the annual meeting of the American Educational Research Association, Los Angeles, CA.

Fraser, B. J. (1982). Differences between student and teacher perceptions of actual and preferred classroom learning environment. Educational Evaluation and Policy Analysis, 4, $511-519$.

Fraser, B., \& Fisher, D. (1983). Student achievement as a function of person environment fit: A regression surface analysis. British Journal of Educational Psychology, 53, 89-99.

Fraser, B. J., \& O'Brien, P. (1985). Student and teacher perceptions of the environment of elementary school classrooms. Elementary School Journal, 85, 567-580.

Glass, G. V., McGaw, B., \& Smith, M. L. (1981). Meta-analysis in social research. Beverly Hills, CA: Sage.

Harter, S., Whitesell, N., \& Kowalski, P. (1986). The effects of educational transitions on children's perceptions of competence and motivational orientation. Manuscript submitted for publication.

Hawkins, J. A., \& Berndt, T. J. (1985, April). Adjustment following the transition to junior high school. In G. R. Adams (Chair), School transitions: Positive and negative associations for social, emotional, and academic development. Symposium conducted at the biennial meeting of the Society for Research in Child Development, Toronto.

Hunt, D. E. (1975). Person-environment interaction: A challenge found wanting before it was tried. Review of Educational Research, 45, 209-230.

Lee, P. (1979). A developmental study of children's prerogatives and constraints in several domains of school experience. (Grant No. NIE-G-78-0033). Washington, DC: National Institute of Education.

Lee, P., Statuto, C., \& Kedar-Voivodas, G. (1983). Elementary school children's perceptions of their actual and ideal school experiences: A developmental study. Journal of Educational Psychology, 75, 838-847.

Lewin, K. (1935). A dynamic theory of personality. New York: McGraw-Hill.

Mac Iver, D., Klingel, D. M., \& Reuman, D. A. (1986, April). Students' decision-making congruence in mathematics classrooms: A person-environment fit analysis. Paper presented at the annual meeting of the American Educational Research Association, San Francisco.

Midgley, C., Feldlaufer, H., \& Eccles, J. S. (1987). The transition to junior high school: Beliefs of pre-and post-transition teachers. Manuscript submitted for publication.

Moos, R. H. (1979). Evaluating educational environments. San Francisco: Jossey-Bass.

Murray, H. A. (1938). Explorations in personality. New York: Oxford University Press.

Nottelmann, E. D. (1982, March). Children's adjustment in school: The interaction of physical maturity and school transition. Paper presented at the annual meeting of the American Educational Research Association, New York.

Power, C. (1981). Changes in students' attitudes towards science in the transition between Australian elementary and secondary schools. Journal of Research in Science Teaching, 18, 33-39.

Reuman, D. A., Mac Iver, D., Klingel, D. M., Midgley, C., Feldlaufer, H., \& Hermalin, A. B. (1984, August). Decision-making in junior high school mathematics: Student-classroom 
discrepancy. Paper presented at the annual meeting of the American Educational Research Association, Toronto.

Rounds, T. S., \& Osaki, S. Y. (1982, March). The social organization of classrooms: An analysis of sixth-and seventh-grade activity structures. Paper presented at the annual meeting of the American Educational Research Association, New York.

Simmons, R. G., Blyth, D. A., Van Cleave, E. F., \& Bush, D. M. (1979). Entry into early adolescence: The impact of school structure, puberty, and early dating on self-esteem. American Sociological Review, 38, 553-568.

Schulenberg, J. E., Asp, C. E., \& Petersen, A. C. (1984). School from the young adolescent's perspective: A descriptive report. Journal of Early Adolescence, 4, 107-130.

Thornburg, H. D., \& Jones, R. M. (1982). Social characteristics of early adolescents: Age versus grade. Journal of Early Adolescence, 2, 229-239.

Trebilco, G. R., Atkinson, E. P., \& Atkinson, J. M. (1977, November). The transition of students from primary to secondary school. Paper presented at the annual meeting of the Australian Association for Research in Education, Canberra.

Wolfson, B. J., \& Nash, S. (1968). Perceptions of decision-making in elementary-school classrooms. Elementary School Journal, 69, 89-93.

Wolfson, B. J., \& Nash, S. (1965). Who decides what in the classroom? Elementary School Journal, 65, 436-438.

Reprint requests should be addressed to:

Carol Midgley

Achievement Research Laboratory

Institute for Social Research

University of Michigan

Box 1248

Ann Arbor, MI 48106 